\title{
EPISTEMOLOGÍAS DEL SUR Y LUCHAS LGTB: CONFLUENCIAS Y DESAFÍOS*
}

\author{
Antoni Aguiló Bonet \\ Centro de Estudos Sociais da Universidade de Coimbra \\ http://dx.doi.org/10.5209/rev_NOMA.2016.v47.n1.52401
}

\begin{abstract}
Resumen: El objetivo principal de este artículo es revelar puntos de confluencia entre las epistemologías del sur propuestas por Boaventura de Sousa Santos y la teoría queer, de modo a establecer las bases y desafíos de una teoría queer del sur que asume que el combate contra la heteronormatividad forma parte de una lucha más amplia contra las diferentes formas de colonialidad, el occidentalismo, el sexismo, la reificación del sentido común y la explotación de los individuos y grupos subalternos.
\end{abstract}

Palabras clave: epistemologías del sur, teoría queer, colonialidad, heteronormatividad, LGTB

Abstract: The main aim of this paper is to reveal common ground between epistemologies of the South proposed by Boaventura de Sousa Santos and queer theory, in order to lay the foundations and challenges of a South queer theory which assumes that the fight against heteronormativity forms part of a broader struggle against various forms of coloniality, occidentalism, sexism, reification of common sense and the exploitation of subaltern groups and individuals.

Keywords: Epistemologies of the South, Queer Theory, Coloniality, Heteronormativity, LGTB

\section{Colonialidad y heteronormatividad}

Dice Boaventura de Sousa Santos (2009) que la realidad está atravesada por líneas metafóricas que crean abismos de silencio y nulidad. Son espacios de negación radical de la humanidad, de marginación e invisibilidad al que se han visto relegadas las poblaciones del sur global ${ }^{1}$ oprimidas por el dominio colonial, capitalista y patriarcal en sus diversas expresiones, así como por el resto de naturalizaciones de la desigualdad. Entre otros colectivos, allí se encuentran mujeres atenazadas por la violencia patriarcal, migrantes indocumentados fuera de la ley, personas obligadas a trabajar en condiciones

\footnotetext{
* Esta publicación ha sido posible gracias al apoyo financiero de la Fundação para a Ciência e a Tecnologia (FCT) a través de su concurso público para la atribución de becas de investigación de doctorado y postdoctorado 2014, que cuenta con un presupuesto compartido por fondos del Ministerio de Educación y Ciencia de Portugal y el Fondo Social Europeo. También es fruto de las reflexiones hechas en el marco de proyecto "ALICE - Strange Mirrors, Unsuspected Lessons: Leading Europe to a new way of sharing the world experiences", coordinado por Boaventura de Sousa Santos en el Centro de Estudos Sociais de la Universidade de Coimbra. El proyecto recibe fondos del Consejo Europeo de Investigación a través del séptimo Programa Marco de la Unión Europea (FP/2007-2013) / ERC Grant Agreement $n^{\circ} 269807$.

1 No se trata de un sur geográfico, sino de un sur metafórico que alude a un "campo de desafíos epistémicos que pretende reparar los daños e impactos causados históricamente por el capitalismo en su relación colonial con el mundo" (Santos y Meneses, 2014: 10). Como metáfora, incluye también el sur que existe en el interior del norte global (grupos oprimidos, marginados y subalternos sometidos al dominio capitalista, colonial y patriarcal) que resiste contra la opresión, la explotación y la exclusión. No incluye el sur imperial (élites occidentales u occidentalizadas) que reproduce en el sur geográfico los intereses del norte.
} 
de esclavitud, enfermos mentales en situación de animalidad y cuerpos estigmatizados por la presencia del $\mathrm{VIH}$.

Según Santos, la realidad está dividida en dos zonas contrapuestas separadas por líneas abismales a la vez ontológicas y epistemológicas: la región de "este lado de la línea" y la región del "otro lado de la línea". Las líneas no representan posiciones fijas e inmutables, sino determinadas posiciones en un campo de relaciones de poder, por lo que se producen desplazamientos de un lado a otro que se fundamentan en el acceso a recursos materiales y simbólicos y, en último término, a lo que Frantz Fanon (2009) caracteriza como zonas de ser y no ser.

Entre ambas zonas se levantan fronteras tanto físicas como simbólicas. Como observa Santos (2009), la característica principal del llamado "pensamiento abismal" es la imposibilidad de la copresencia igualitaria de ambos lados de la línea. La consecuencia de esta división es la instauración de una jerarquía ontológica entre este lado de la línea (los seres que prevalecen como visibles y existentes) y el otro lado de la línea (los seres inferiorizados y producidos como no existentes). De este modo, la región que se halla en este lado es un territorio domesticado, previsible y protegido, regido por el Estado de derecho, los derechos humanos y la democracia liberal. Por el contrario, el otro lado de la línea constituye un espacio salvaje e incierto en el que imperan dinámicas de apropiación y violencia. Como consecuencia, sus poblaciones pasan a ser devaluadas como intrínsecamente inferiores por un sistema de dominación que determina una condición de subhumanidad, regida por una lógica de producción de no existencia "siempre que una cierta entidad es descalificada y considerada invisible, no inteligible o desechable” (Santos, 2010: 34).

Como perspectiva de análisis, el pensamiento abismal permite explorar la relación entre colonialidad y heteronormatividad mediante el reconocimiento de esta última como parte de la matriz colonial, reflexionando al mismo tiempo sobre cómo se construye y naturaliza la invisibilidad en la sociedad. Atendiendo a las aportaciones del pensamiento crítico latinoamericano a través del grupo de investigación Modernidad/Colonialidad, el término colonialismo hace referencia a la dominación política, económica, militar y cultural de una potencia sobre otra. El concepto de colonialidad, por su parte, alude a un residuo sociohistórico del colonialismo formal que pervive en el imaginario social (Quijano, 1993; Mignolo, 2003; Castro-Gómez, 2011). Un remanente del colonialismo que, como dice Ngũgĩ wa Thiong'o (1994: 16), actúa sobre el "universo mental de los colonizados" y ejerce "el control, a través de la cultura, de cómo las personas se percibían a sí mismas y su relación con el mundo". ${ }^{2}$ Según Ramón Grosfoguel (apud Montes y Busso, 2012: 74), la colonialidad remite a "un patrón de poder que se inaugura con la expansión colonial europea a partir de 1492 y donde la idea de raza y la jerarquía etno-racial global atraviesa todas las relaciones sociales existentes tales como la sexualidad, género, conocimiento, clase, división internacional del trabajo, epistemología, espiritualidad, etc. y que sigue vigente aun cuando las administraciones coloniales fueron casi erradicadas del planeta". Se trata, pues, de una estructura de dominación más profunda y duradera que el colonialismo.

\footnotetext{
${ }^{2}$ Traducción propia.
} 
Catherine Walsh (2008: 136-138) precisa que el patrón de poder colonial gravita sobre cuatro ejes interconectados con sentidos sociales, culturales, políticos, epistémicos y existenciales. El primero es la colonialidad del poder (Quijano, 2000, 2007), referido al establecimiento de un sistema de clasificación social que pivota en torno a la categoría "raza" como criterio para distribuir, dominar y explotar a la población mundial. Este sistema de clasificación incluye aspectos como el control de la economía (explotación de mano de obra, control de recursos naturales, apropiación del espacio, etc.) y el control de la autoridad (administración pública, instituciones jurídicas y políticas, ejército, etc.). El segundo es la colonialidad del saber, que considera el eurocentrismo como la única perspectiva verdadera del conocimiento y desacredita otras racionalidades, epistemologías y saberes, proyectándose en aspectos como el control de la educación (Lander, 2000). El tercero es la colonialidad del ser (Maldonado-Torres, 2007), que remite a la inferiorización, subalternización y deshumanización de los sujetos marginados por el pensamiento abismal, e incluye dimensiones como la formación de la subjetividad o el control de género y la sexualidad (Mignolo et al. 2008; Lugones, 2008). El cuarto, por último, es la colonialidad de la naturaleza, basada en la oposición binaria ser humano/naturaleza (Alimonda, 2011).

Las relaciones coloniales se basan en la instrumentalización y transformación del otro en objeto. "Colonialismo son todos los trueques, los intercambios, las relaciones, donde una parte más débil es expropiada de su humanidad" (Santos, 2006: 50). O en otros términos: "El colonialismo es la concepción que ve al otro como objeto, no como sujeto" (Santos, 2005: 106).

Un tipo de relación que mantiene la línea abismal de la colonialidad es la diferenciación desigual. Parte del principio colonial de que la diferencia necesariamente significa desigualdad, creada a partir de categorías de clasificación social que el pensamiento abismal instrumentaliza para naturalizar jerarquías de dominio y autoridad (Santos, 1998: 414). La diferenciación desigual consiste en una relación de poder donde la alteridad se construye mediante la atribución de características que intervienen en la configuración de la identidad y la diferencia. Una de las partes en relación se autolegitima como superior por naturaleza. Se establece, por tanto, una ecuación entre diferencia e inferioridad que implica un sistema de posiciones ordenadas jerárquicamente a las que se asignan determinadas identidades sociales, políticas o culturales que normalizan actitudes como el racismo, el sexismo o la homofobia. En virtud de ello, la diferenciación desigual tiene poder para silenciar o invisibilizar la diferencia, pero también para jerarquizarla y dominarla.

En consecuencia, el patrón colonial de poder se expresa en forma de discursos, ${ }^{3}$ prácticas y marcos institucionales impregnados por valores y creencias que revelan la incorporación naturalizada de las desigualdades y tratan de perpetuarlas con un llamamiento a la necesidad de respetar la tradición que se considera amenazada. Estos discursos están atravesados por un mecanismo de producción de no existencia: la "monocultura de la

${ }^{3}$ En el pensamiento de Foucault (1997: 81), discurso se refiere a "prácticas que forman sistemáticamente los objetos de que hablan". Los discursos son formaciones epistémicas cuya función principal es fundar y difundir lenguajes de verdad que explican, descubren, clasifican, controlan y jerarquizan sujetos y relaciones sociales. 
naturalización de las diferencias" (Santos, 2005: 161), que convierte las diferencias en argumentos para imponer y ocultar jerarquías (de clase, étnicas, de género, entre otras).

La diferenciación desigual de las personas LGTB $^{4}$ se ha construido históricamente bajo el régimen de la heteronormatividad, concebida como:

"Aquellas instituciones, estructuras de comprensión y orientaciones prácticas que hacen no sólo que la heterosexualidad parezca coherente (es decir, organizada como sexualidad) sino también que sea privilegiada. Su coherencia es siempre provisional y su privilegio puede adoptar varias formas (que a veces son contradictorias): pasa desapercibida como lenguaje básico sobre aspectos sociales y personales; se la percibe como un estado natural; también se proyecta como un logro ideal o moral" (Berlant y Warner, 2002: 230).

De este modo, la heteronormatividad constituye un sistema en el que la conducta sexual y las relaciones de parentesco se organizan en torno a la heterosexualidad, convertida en el orden "natural" culturalmente aceptado (Guasch, 2000). Ello conduce forzosamente a la adopción de un punto de vista hegemónico sobre el sexo, la sexualidad y las identidades de género que impregna las instituciones y regulaciones que afectan a la vida sexual y reproductiva de los miembros de la sociedad, así como los códigos morales que influencian las decisiones personales.

El núcleo de la heteronormatividad se asienta en el binarismo de la diferencia sexual: el supuesto de que la humanidad está naturalmente dividida en hombres y mujeres que muestran comportamientos femeninos y masculinos vinculados a su sexo biológico. Un segundo binarismo aparejado al anterior es la diferenciación entre normal y anormal. La supuesta naturalidad de ambas dicotomías apoya la jerarquía patriarcal y heteronormativa de sexos y géneros existente.

Guiadas por una ideología patriarcal y heteronormativa, instituciones y disciplinas modernas (entre las que se incluyen el Estado, los sistemas educativos, los medios de comunicación, la medicina, el derecho y la religión) instituyeron discursos de odio y discriminación que configuraron la definición de la diversidad sexual como desviación y la representación de las personas LGTB como inferiores, inmorales y degeneradas en cuanto marcadas por los estigmas de la enfermedad, el delito y el pecado (Butler, 2004). A partir de ellos, instauraron un canon sexual hegemónico que constituye el patrón desde el que se define la desviación a la norma y sus formas de control. Un canon que eleva a patrón de referencia universal al varón blanco, adulto, propietario, cristiano y heterosexual; regula las conductas socialmente legítimas a partir de la biologización esencialista del binomio hombre/mujer; exalta el amor romántico como práctica cultural y condición de autorrealización personal (Illouz, 2009); y produce como no existentes construcciones del cuerpo, del género y la sexualidad fuera de las narrativas euroamericanas dominantes. Esta ideología es un reflejo de la colonialidad arraigada en nuestras sociedades

\footnotetext{
${ }^{4}$ Utilizo la terminología LGTB en un sentido amplio e inclusivo que no sólo incluye a lesbianas, gays, bisexuales y trans, sino también a personas intersex, queer y aliados.
} 
que, como afirma Aníbal Quijano (2007: 95), se sostiene sobre "una concepción de humanidad, según la cual la población del mundo se diferencia en inferiores y superiores, irracionales y racionales, primitivos y civilizados, tradicionales y modernos".

\section{Hacia una epistemología queer del sur}

Partiendo de estas premisas introductorias, el objetivo de este trabajo es acercarnos a los retos globales que hoy plantea la lucha contra la heteronormatividad, reflexionando a partir de las epistemologías del sur planteadas por Boaventura de Sousa Santos en articulación con la teoría queer. Se pretende, así, crear una confluencia teórica y práctica entre ambas perspectivas, delineando los contornos generales de una teoría queer posabismal que asuma un discurso crítico de la colonialidad -incluso de la que pervive en el interior de la teoría queer del norte global- y proponga estrategias de desenganche y superación (Pereira, 2015).

En sintonía con un conjunto de perspectivas críticas con las formas de colonialidad, las epistemologías del sur asumen el reto epistemológico y metodológico de desarrollar un pensamiento posabismal capaz de "aprender que existe el Sur; aprender a ir hacia el Sur; aprender a partir del Sur y con el Sur" (Santos, 2009: 287). En este sentido, constituyen un reclamo de "nuevos procesos de producción y de valoración de conocimientos válidos, científicos y no científicos, y de nuevas relaciones entre diferentes tipos de conocimiento, a partir de las prácticas de las clases y grupos sociales que han sufrido de manera sistemática las injustas desigualdades y las discriminaciones causadas por el capitalismo y por el colonialismo" (Santos, 2011: 35).

Las epistemologías del sur son una propuesta de transformación de la manera de producir conocimiento basada en las siguientes premisas (Santos, 2009, 2010, 2011, 2012):

1. Reconocer que "todo conocimiento válido siempre es contextual, tanto en términos de diferencia cultural como de diferencia política" (Santos y Meneses, 2014: 7-8).

2. Lo que comúnmente entendemos por epistemología es, en realidad, una epistemología local, contextual, "basada en una doble diferencia: la diferencia cultural del mundo moderno cristiano occidental y la diferencia política del colonialismo y el capitalismo" (Santos y Meneses, 2014: 8).

3. Lo invisible, lo inexistente, siempre es activamente producido como no existente.

4. La comprensión del mundo excede la comprensión occidental del mundo.

5. La diversidad del mundo es infinita y se traduce de maneras plurales en la teoría y la práctica.

6. Es necesario crear inteligibilidad recíproca entre saberes y experiencias del mundo.

7. Diverso no significa necesariamente desunido y unido no significa necesariamente uniforme. 
8. Lo igual no es necesariamente idéntico y lo diferente no es necesariamente inferior o superior.

9. Hay un desperdicio epistemológico que no da cuenta de la infinita diversidad de experiencias válidas de conocimiento a partir de las cuales se estructuran las diferentes prácticas sociales y políticas. Buena parte de este desperdicio es alentado por los procesos internos de colonización de las ciencias sociales que operan con una mirada colonial, apreciable en las maneras de investigar y producir conocimiento.

10. En el mundo no faltan alternativas de emancipación, ni tampoco ausencias $^{5}$ y emergencias ${ }^{6}$ llenas de posibilidades.

Por su parte, la teoría queer, como conjunto amplio y heterogéneo de teorías que engloban contribuciones diversas, contribuye a repensar "impensar", en palabras de Immanuel Wallerstein (1999)- las cuestiones de género y la sexualidad humana desde perspectivas epistémicas que desnaturalizan las identidades sexuales tradicionales, rompen los cánones heteronormativos universalistas y ofrecen alternativas para combatir el patriarcado y la heteronormatividad (León y Mtetwa, 2003; Sabariego, 2004; Córdoba, Sáez y Vidarte, 2005; Kirsch, 2013).

El punto de partida intelectual de la teoría queer fue brillantemente descrito por Eve Kosofsky Sedgwick cuando en la introducción de una de sus obras más reconocidas afirma:

"La comprensión de casi todos los aspectos de la cultura occidental moderna no sólo es incompleta, sino que está perjudicada en lo esencial en la medida en que no incorpora un análisis crítico de la definición moderna de la homo/heterosexualidad; y partirá del supuesto que el terreno más apropiado para iniciar este análisis crítico es la perspectiva relativamente dispersa de la teoría moderna gay y antihomofóbica" (Sedgwick, 1998: 11)

De acuerdo con Tadeu da Silva, dado su carácter transgresor y rompedor de límites y tradiciones, la teoría queer:

"Nos obliga a considerar lo impensable, lo que está prohibido pensar, en lugar de limitarse simplemente a considerar lo pensable, lo que está permitido pensar. [...] Lo queer se vuelve, así, una actitud epistemológica que no se limita a la identidad y al conocimiento sexual, sino que se extiende al conocimiento y la identidad en general. Pensar queer significa cuestionar, problematizar,

\footnotetext{
${ }^{5}$ Utilizo el término ausencia en alusión a lo que Santos (2005) propone como una "sociología de las ausencias", un procedimiento sociológico no convencional cuyo objetivo es recuperar experiencias sociales desacreditadas y desperdiciadas por el pensamiento abismal. Su principal cometido es dilatar el presente, expandiendo el campo de las experiencias disponibles y revelando la diversidad y multiplicidad de prácticas y agentes sociales.

"El concepto de emergencia se refiere a la "sociología de las emergencias" de Santos (2005), que busca llevar a cabo una ampliación simbólica de los saberes y prácticas a partir de la identificación de pistas, indicios y tendencias de futuro en lo existente que apuntan a alternativas futuras concretas.
} 
impugnar todas las formas convencionales de conocimiento e identidad. La epistemología queer es, en este sentido, perversa, subversiva, impertinente, irreverente, profana, carente de respeto" (1999: 197). ${ }^{7}$

Como explica Annamarie Jagose (1996), la apropiación política y académica del término se produjo en Estados Unidos y Europa en las últimas décadas del siglo XX, para expandirse después a otras regiones. Queer procede del inglés y originalmente tenía una connotación peyorativa que puede traducirse por "extraño" o "raro", en el sentido de algo que no puede clasificarse claramente bajo los parámetros del sistema sexo/género hegemónico (Rubin, 1986). ${ }^{8} \mathrm{Al}$ final de la década de 1980, el concepto fue reapropiado de manera transgresora en Estados Unidos por el movimiento de prostitutas, seropositivos, trans, lesbianas, negras y migrantes chicanas como instrumento de denuncia de lo que se considera normal y, al mismo tiempo, como herramienta de visibilidad respecto al movimiento gay urbano, blanco y de clase media con un proyecto de integración normalizada en la sociedad capitalista de consumo (Herrera Gómez, 2010: 271). Desde entonces, el término viene ganando terreno entre las luchas críticas con el orden patriarcal y heteronormativo, en especial las del movimiento LGTB (Loovas et al. 2013).

La reivindicación del significado transgresor de lo queer visibilizó su capacidad de crítica desde los márgenes, de denuncia desde el otro lado de la línea, lo que permite considerar la posibilidad de un potencial descolonizador, de apertura a perspectivas marginadas que ponen en duda visiones reduccionistas sostenidas por élites sociales, políticas o económicas que ocupan posiciones de poder. En concordancia con la perspectiva posabismal de las epistemologías del sur, la teoría queer plantea resignificaciones, prácticas y posicionamientos epistemológicos que, al reconocer los saberes, prácticas y memorias de sujetos invisibilizados y socialmente inferiorizados, atentan contra la lógica de la colonialidad. Ello permite contribuir a generar nuevas interpretaciones y nuevos procesos, a resquebrajar viejos consensos y construir nuevos acuerdos, a inventar nuevas utopías y a crear otras maneras de vivir el amor, la sexualidad y de habitar nuestros cuerpos.

Desafiar el binarismo sexo/género y el dualismo mujer/femenino y hombre/masculino es un propósito que la teoría queer coloca en la agenda y el debate feminista. Desaprender críticamente estos conceptos también es una acción política cuyo objetivo es combatir el patriarcado y la colonialidad de la sexualidad inscrita tanto en los cuerpos de las mujeres como en los cuerpos de las personas LGTB marcados por la diferenciación desigual.

De ahí la necesidad de nuevos enfoques teórico-metodológicos que permitan "ver" las relaciones coloniales en el marco de la heteronormatividad y vincularlas con otras categorías que se cruzan entre sí, como clase social, edad, raza y religión, entre otras (Trujillo, 2014: 60). De este modo, pueden perfilarse, a grandes rasgos, los contornos de una epistemología queer del sur,

\footnotetext{
${ }^{7}$ Traducción propia.

${ }^{8}$ Gayle Rubin (1986: 97) define el sistema sexo/género como "el conjunto de disposiciones por el que una sociedad transforma la sexualidad biológica en productos de la actividad humana, y en el cual se satisfacen esas necesidades humanas transformadas".
} 
como la representada, por ejemplo, por el feminismo negro y lésbico de Audre Lorde (2003) y el feminismo indígena y lésbico de Julieta Paredes (2008). ${ }^{9}$

Desde estas coordenadas, una epistemología queer del sur significa romper las concepciones tradicionales, patriarcales, esencialistas y conservadoras de sexo y género. Transgredir los binarismos y las definiciones de sexualidad impuestas por sociedades machistas, etnocéntricas y patriarcales. Denunciar los sesgos e intereses de un pensamiento abismal sobre la sexualidad para tensionar conceptos como hombre, mujer, masculino, femenino, gay, lesbiana, bisexual, etc. Significa, también, involucrarse en los debates y las acciones del pensamiento descolonial para resignificar la diferencia colonial desde ecologías de saberes y prácticas, creando condiciones para nuevas condiciones de saber y poder compartido que visibilicen sin jerarquizarlas experiencias producidas como inexistentes y produzcan un conocimiento emancipador que transite de la colonialidad a la solidaridad. Por tanto, las epistemologías queer del sur no sólo buscan un replanteamiento conceptual, sino también la construcción de prácticas políticas y epistémicas que transformen estructuras opresoras de poder/saber operativas en el Estado, la sociedad y el interior de los propios movimientos sociales y disciplinas académicas.

\section{Emancipación LGTB: retos desde el sur global queer}

Atravesar las líneas abismales implica cruzar las fronteras ontológicas para hacerse visible y cuestionar la condición de sujeto dominado. Hace casi medio siglo, una de esas fronteras empezó a resquebrajarse gracias a la rebelión de Stonewall, que marcó el surgimiento del movimiento internacional de lucha por el reconocimiento de los derechos civiles LGTB en Norteamérica y Europa occidental. Como otros bares semejantes, el Stonewall Inn, en el barrio neoyorkino de Greenwich Village, era un gueto nocturno donde la comunidad LGTB podía hacer visible su condición y protegerse del desprecio social. Entre su clientela habitual se encontraban travestis, drag queens, transexuales, hippies, gays, lesbianas, inmigrantes latinos, prostitutas y chaperos.

La madrugada del 28 de junio de 1969, en lugar de huir de la redada que se producía, alegando que se estaban vendiendo bebidas alcohólicas sin licencia, los clientes se rebelaron contra la violencia y la represión policial, que incluía la prisión de empleados, de clientes sin identificación y de individuos vestidos de manera no acorde con su sexo. La chispa de la liberación se encendió en forma de un movimiento popular de resistencia que se enfrentó a la policía en las calles durante varios días. Durante la confrontación se corearon lemas como "ipoder gay!", inaudito hasta entonces en un país en el que cuarenta y nueve Estados tenían leyes antihomosexuales (Carter, 2010; Duberman, 2013).

Desde Stonewall, los movimientos LGTB han aumentado en todo el mundo para abrir caminos de transformación hacia sociedades igualitarias. La visibilización de las relaciones de poder en la esfera de la sexualidad, las luchas por el reconocimiento del matrimonio igualitario, de otros modelos familiares, por la inclusión de la identidad de género entre los motivos de discriminación, por la libre disposición del cuerpo, por la construcción de

\footnotetext{
${ }^{9}$ Para profundizar en las aportaciones de los feminismos contrahegemónicos a los estudios sobre (pos)colonialidad, véase la referencia Bidaseca y Vázquez Laba (2011).
} 
masculinidades antipatriarcales, el activismo contra el SIDA y la denuncia de las actitudes heteronormativas de la izquierda son algunos de los frentes de batalla de la agenda cultural y política que las revueltas de Stonewall contribuyeron a desencadenar.

No obstante, más allá de las conquistas sociales y jurídicas, e independientemente de los contextos de referencia, la lucha por la igualdad real del colectivo LGTB continúa. La heteronormatividad está institucionalizada y organizada en un modelo de sociedad patriarcal, capitalista y heterosexista globalizado en el que la heterosexualidad se considera la condición sexual natural, que funciona como un modo de regulación social que confiere o retira determinados privilegios.

Si entendemos que los derechos son conquistas sociojurídicas desde abajo o, en palabras de Joaquín Herrera Flores (2008: 25), "procesos de lucha por el acceso a los bienes porque vivimos inmersos en procesos jerárquicos y desiguales que facilitan u obstaculizan su obtención", queda un largo camino para que estos procesos de subversión y lucha no queden en una aspiración insatisfecha y se traduzcan en lógicas de pensamiento, formas de articulación y vida que contengan propuestas con una dimensión de cambio civilizatorio.

La subversión puede entenderse como una pluralidad de discursos y prácticas que abarcan desde formas físicas y visibles de resistencia a formas más sutiles y simbólicas. La subversión que los colectivos LGTB han protagonizado a lo largo de la historia ha permitido combatir formas de violencia física y simbólica ${ }^{10}$ que siguen formando parte de nuestras sociedades. Luchar por el reconocimiento efectivo de la diversidad sexual y de género es luchar para que la diversidad no sea negada por estrategias coloniales de diferenciación desigual, que convierten lo diferente en inferior y mantienen a las personas LGTB en un estado de subhumanidad popularmente llamado armario. ${ }^{11}$ Es abrir los armarios impuestos por la sociedad que alimentan el miedo y la soledad y recluyen dentro -epistemológica, política y socialmente- las sexualidades "periféricas", como las Ilama Foucault (2007: 56),

Subvertir la heteronormatividad requiere de teorías y prácticas que pongan en tela de juicio las asunciones heteronormativas naturalizadas, valoren las perspectivas y experiencias del sur global, produzcan subjetividades rebeldes e introduzcan cambios en la cultura de la movilización colectiva, a fin de forjar nuevas articulaciones que superen la fragmentación identitaria de las luchas. De aquí emerge un campo de desafíos y oportunidades para que los movimientos LGTB, las investigaciones posicionadas en el ámbito de la teoría queer $\mathrm{y}$, en general, las personas e instituciones comprometidas con la transformación social emancipadora, construyan un proyecto social y político contrahegemónico capaz de potenciar su combatividad a favor de la

10 La violencia simbólica se refiere a los modos internalizados, casi inconscientes, de dominación social y cultural. Véase al respecto Bourdieu (1985).

${ }^{11}$ En su obra Epistemología del armario, Kosofsky Sedgwick (1998) complejiza el concepto de salir del armario para señalar que dicha salida nunca es absoluta, de manera que siempre se está dentro y fuera al mismo tiempo. Para Sedgwick, el armario funciona como un medio de regulación social que por un lado confiere privilegios a quienes se relacionan con personas de diferente sexo y mantienen los valores e instituciones del orden heteronormativo y, por otro, subalterniza e invisibiliza en el espacio público a quienes mantienen relaciones con personas del mismo sexo. 
emancipación social y sexual. De esta forma, asegurar la continuidad de los derechos conquistados y ampliarlos en la dirección señalada implica revisar algunas cuestiones que surgen de las realidades mundiales, pero también de las tensiones y conflictos presentes en la relación con otros actores aliados en las causas de la igualdad y la diversidad. Estas cuestiones remiten al menos a ocho desafíos fundamentales:

Despenalizar. Según datos recientes de la Asociación Internacional de Lesbianas, Gays, Bisexuales, Trans e Intersex (ILGA), de los más de 190 países que actualmente reconoce la ONU, en al menos setenta y seis las prácticas no heterosexuales están legalmente criminalizadas (Carroll e Itaborahy, 2015). Además, la igualdad jurídica no se corresponde con la igualdad social: el acoso escolar a los adolescentes LGTB $^{12}$ (sobre todo trans) es una alarmante realidad y en muchos lugares una pareja del mismo sexo no puede caminar de la mano sin temor a ser agredida, lo que evidencia la discriminación social del colectivo (Ferreira, 2015).

En este contexto, despenalizar quiere decir garantizar una inclusión legal que no sólo deje de perseguir y castigar por ley las relaciones entre personas LGTB, sino que reconozca jurídicamente sus derechos civiles (matrimonio, parentalidad, libertad de expresión y asociación, etc.), que son la condición básica para el respeto y el reconocimiento de la ciudadanía íntima, sexual y reproductiva (Plummer, 2003; Santos, 2013). Despenalizar es implementar los mecanismos legislativos e institucionales que permiten vivir la sexualidad con dignidad y libertad.

Despatologizar. Significa desnaturalizar la medicalización y biologización de las identidades de género y los comportamientos sexuales, reconocer la pluralidad existente de géneros y sexualidades (poliamorosos, queers, parejas abiertas, genderfuckers, BDSM, crossdressers, gender bender, intersexualidades, etc.), combatir el poder biomédico como discurso hegemónico sobre los cuerpos y las sexualidades, cuestionar los prejuicios médicos y la legitimidad científica de los pretendidos diagnósticos ("trastorno", "histeria") y terapias, insertando los discursos patologizantes en el ámbito de relaciones de poder que delimitan la frontera entre lo que se considera "normal" y lo que se considera "patológico" (Tosh, 2015; Missé y Coll-Planas, 2010; Galofre y Missé, 2015).

El reto de la despatologización plantea la retirada urgente de la transexualidad de los manuales de psiquiatría, en la línea de la última edición (2013) del Manual Diagnóstico y Estadístico de Enfermedades Mentales (DSM-5), elaborado por la Asociación Americana de Psiquiatría. Sin embargo, la Clasificación Internacional de Enfermedades (ICD-10 ${ }^{13}$ ), de la Organización Mundial de la Salud, la sigue incluyendo en el capítulo relativo a los "trastornos mentales y del comportamiento".

\footnotetext{
${ }^{12}$ El informe Homofobia y bifobia en las aulas 2013 revela que el $81 \%$ del alumnado madrileño que se define como lesbiana, gay o bisexual no se atreve a salir del armario en su centro educativo. El $41,82 \%$ considera que el profesorado hace poco o nada ante los insultos homófobos en el aula. Y, de los que han salido del armario, el porcentaje de alumnos que han sufrido violencia física es tres veces mayor que el de los que no han salido del armario (COGAM, 2013).

${ }^{13}$ http://apps.who.int/classifications/icd10/browse/2010/en
} 
Despatriarcalizar. Es erradicar el machismo, la misoginia, la lesbofobia y la transfobia aún habituales entre varones homosexuales y bisexuales, plantar cara a la discriminación sistémica que sufren las mujeres, atender a la intersección entre diferentes formas de discriminación (por edad, género, etnia, condición sexual, clase social, etc.), mostrar que los labios de las mujeres no están sellados y que su rebeldía se organiza en todo el mundo contra el patriarcado capitalista y heterosexista que las explota, reprime y mata.

Desmercantilizar. El movimiento de liberación LGTB de 1970 surgió en una sociedad capitalista de clases. El proceso de reestructuración capitalista articulado en torno a la globalización neoliberal ha abierto espacio para la comunidad LGTB. La intensa penetración del mercado en su vida cotidiana ha creado formas de existencia, relación y visibilidad mercantilizadas en torno a bares, negocios de moda y publicaciones comerciales, entre otros servicios, al tiempo que promueve una despolitización significativa de sus espacios y acciones, a menudo regidos por lógicas lucrativas vacías de contenido social y político. Desmercantilizar es denunciar la falsa emancipación capitalista basada en el consumo, dejar de vivir la sexualidad a través de la compra de bienes y servicios, desmontar los estereotipos comerciales reservados por el capitalismo al público LGTB, crear espacios de contrapoder no dominados por relaciones de mercado y fortalecer, en síntesis, la militancia y el compromiso de transformación anticapitalista.

Descolonizar. Hay una tendencia a contar la historia de la emancipación LGTB por medio de un discurso lineal y eurocéntrico: desde la invisibilidad y la represión premoderna hasta la conquista de la visibilidad y la libertad sexual moderna, como si antes -y más allá- de Stonewall, Chueca o San Francisco no hubiera resistencia y disidencia sexual. Esta tendencia ha contribuido a hipervisibilizar al varón homosexual blanco, adulto joven y de clase media en detrimento de las luchas de homosexuales, bisexuales y trans de color, de las personas LGTB con ingresos reducidos, de aquellas que viven con discapacidades, presentan una edad avanzada o pertenecen a minorías étnicas. De hecho, la revuelta de Stonewall fue propiciada por travestis y en ella lesbianas y gays latinos tuvieron un papel relevante.

Un problema relacionado es que la mayor parte de la literatura científica internacional sobre género y sexualidad utiliza marcos conceptuales y metodológicos derivados de la experiencia del norte global y presta escasa atención a la producción intelectual de los países del sur, lo que reproduce la "colonialidad del ver" y del saber en la teoría social (Barriendos, 2011; Connell, 2014).

Descolonizar, en este escenario, significa ampliar la mirada a las identidades sexuales y de género invisibilizadas que se construyen dentro y fuera de Occidente: las culturales sexuales del mundo árabe, los imaginarios sexuales japoneses, las sexualidades indígenas, etc., donde quienes mantienen relaciones sexuales con personas del mismo sexo no se identifican necesariamente como homosexuales, trans o bisexuales. Significa disolver las dicotomías de género y las polarizaciones sexuales que la heteronormatividad y el patriarcado establecieron como imágenes especulares del cuerpo, de lo erótico, de lo masculino y lo femenino. Es sospechar de las teorías y disciplinas que reproducen jerarquías naturalizadas para democratizarlas y ampliar las formas de saber y los modos de existencia. Es impulsar la solidaridad sur-sur 
entre las sexualidades no normativas, sobre todo entre las de África y Oriente Medio, donde las comunidades LGBT son menos visibles y los movimientos sociales más duramente reprimidos. Pero también fomentar la solidaridad norte-sur y sur-norte, lo que implica descolonizar los proyectos internacionales de cooperación al desarrollo para poner en marcha alternativas al desarrollo que incluyan en su agenda la diversidad sexual y de género como eje transversal desde el que construir procesos alternativos al proyecto civilizatorio neoliberal, nortecéntrico y heteronormativo (AA.VV, 2013). Y es incorporar en los estudios feministas y LGTB procesos de visibilización de las perspectivas del sur, porque reconocer el trabajo intelectual del sur global es una cuestión de "justicia cognitiva" para acabar con la colonialidad del saber que produce jerarquización y exclusión de saberes (Santos, 2009, 2014).

Desaprender. Quiere decir desenmascarar y, en la medida de lo posible, abandonar el vasto conjunto de técnicas, estrategias y fuentes de opresión (esquemas, teorías, conceptos, estereotipos, percepciones, normas de actuación, hábitos, interpretaciones, etc.) sobre género y diversidad sexual presentadas como verdades sagradas que legitiman el machismo, el sexismo y el heterosexismo. Desaprender es más difícil que aprender, ya que al poner en cuestión los esquemas heredados algo se tambalea, permitiendo a quien desaprende sustituir el prejuicio por la solidaridad, lo que sienta las bases para crear una "ecología de los reconocimientos" (Santos, 2005: 165). En el ámbito de la diversidad sexual, esta ecología desafía la lógica de la clasificación social anclada en la monocultura de la naturalización de las diferencias para convertir diferencias inferiorizantes en diferencias iguales hechas de reconocimientos recíprocos, es decir, diferencias que fuera de las jerarquías que las consagran no tienen sentido. Cuanto mayor sea la diversidad social y cultural de los sujetos colectivos que luchan por la emancipación social, mayor es la necesidad de hacer una ecología de reconocimientos. La lógica ecológica planteada por Sousa Santos pone de relieve la diversidad como virtud y abre espacio para identificar ausencias y emergencias en el campo de género y de la diversidad sexual.

Interseccionalidad. Desafiar cualquier forma de diferenciación desigual exige comprender la interrelación entre las distintas formas de dominación y privilegio, reconocer que género, edad, raza (como constructo sociocultural) y clase social no son ámbitos de experiencia aislados, sino que, como argumenta el análisis intersectorial, son relaciones cruzadas y conflictivas entre sí (McClintock, 1995). Siguiendo a Avtar Brah y Anne Phoenix (2004: 76), la interseccionalidad" $^{14}$ es entendida como "los efectos complejos, irreductibles, variados y variables que se derivan cuando múltiples ejes de diferenciación económica, política, cultural, psicológica, subjetiva y de experiencia- se intersectan históricamente en contextos específicos". ${ }^{15}$ En muchos contextos, resulta muy difícil analizar el discurso y las estrategias de un movimiento LGBT

\footnotetext{
${ }^{14}$ Adriana Piscitelli (2008) recuerda que algunas autoras utilizan el término "categorías de articulación", como Avtar Brah (2004), que tiende a utilizar ambos conceptos indistintamente. Otro término que feministas como, entre otras, Patricia Hill Collins (2000) y Wendy Hulko (2009) suelen utilizar es interlocking oppressions, que puede traducirse por entrecruzamiento de opresiones.

${ }^{15}$ Traducción propia.
} 
sin tener en cuenta cuestiones de discriminación racial y de clase, dado que la marginación se acentúa bajo prácticas capitalistas y coloniales.

La complejidad que recoge este enfoque supone un desafío para los feminismos, las teorías queer y las epistemologías del sur en su afán de producir rupturas no sólo conceptuales sino también prácticas y políticas con las estructuras opresoras de poder, a la vez que interpela la agenda de investigación de las disciplinas académicas y la agenda política de gobiernos, movimientos sociales y otros actores preocupados por el problema de la desigualdad.

Cosmopolitismo insurgente. Vivimos en la época del predominio de la globalización neoliberal, que mercantiliza la vida y globaliza el poder patriarcal y heteronormativo, lo que exige pasar de una política de movimientos a una de intermovimientos capaz de generar nuevas y amplias alianzas entre las redes, plataformas y movimientos que luchan por la emancipación femenina y LGTB, pero también estrategias coordinadas entre los diferentes movimientos que comparten luchas y resistencias contra el sistema patriarcal, heterosexista, racista y clasista. Es lo que desde la perspectiva de las epistemologías del sur viene llamándose cosmopolitismo subalterno: un "cruce de luchas progresistas locales con el objetivo de maximizar su potencial emancipador in loco a través de las uniones translocales/locales" (Santos, 2005: 279).

Cabe, en este sentido, recordar que el movimiento queer surgió precisamente de un cosmopolitismo desde abajo que coaligó al movimiento feminista y homosexual más periférico con personas negras, migrantes, trans, portadoras del $\mathrm{VIH}$ y prostitutas. Al unirse, las redes cosmopolitas pueden llegar a crear las alianzas más improbables e inesperadas, como la que en 1984, en el Reino Unido gobernado por Margaret Thatcher, unió solidariamente a activistas LGTB y al movimiento minero (Kelliher, 2014). Ello permite poner en práctica una ecología de reconocimientos que crea inteligibilidad entre diferentes proyectos de emancipación social y contribuye a nuevas formas de politización que señalan la interseccionalidad de luchas y agendas de cambio social.

No obstante, como advierten Luanna Barbosa e Hilan Bensusan (2012), es fundamental que esta diversidad articulada para la construcción de contrahegemonías desde abajo no quede sofocada por los discursos emancipadores universalistas de Occidente -como por ejemplo el de los derechos humanos-, sino que refleje un "proyecto de horizontalidad de las contraidentidades" que evite la homogeneización de las resistencias y reivindique la polifonía de lenguajes emancipatorios.

Los ochos retos mencionados pueden sintetizarse en un solo desafío transversal: autoempoderarse, que consiste un proceso de autocapacitación, de creación colectiva de conciencia crítica y de poder popular a través del cual las personas y grupos involucrados adquieren la autoestima, los aprendizajes y las habilidades necesarias para transformar las estrategias de segregación ontológica (quiénes son humanos) y de diferenciación desigual en este caso promovidas por la heteronormatividad. Tal y como lo define Marcela Lagarde (2000: 27), "empoderamiento significa, en términos políticos, modificar las pautas políticas que coartan la vida personal y colectiva al crear condiciones para eliminar los poderes personales y sociales que oprimen". 


\section{Conclusiones}

En este trabajo he tratado de esbozar, de manera preliminar, las bases de una epistemología queer a partir de las premisas teóricas e implicaciones normativas de las epistemologías del sur, que pueden resumirse en el triple objetivo de democratizar, descolonizar y desmercantilizar el conocimiento y la práctica social (Santos apud Aguiló, 2010).

El trabajo revela, por un lado, algunas de las invisibilidades y jerarquías sociales naturalizadas que el pensamiento abismal y colonial, como sistema de clasificación social, establece a partir de la monocultura de la naturalización de las diferencias, que transforma estas últimas en desigualdades e institucionaliza un sistema sexo/género que produce capas de subhumanidad y anula la existencia de otro conocimientos y formas de vida, entre ellas las de las personas LGTB y, dentro del propio colectivo, las de los grupos más vulnerables: prostitutas trans, migrantes, refugiados, mayores, menores de edad y personas LGTB en áreas rurales o en situaciones precarias (cárceles, Centros de Internamiento de Extranjeros, etc.), entre otros. Por otro, presenta los principales retos de una epistemología queer posabismal que busca romper la dinámica mediante la cual la ciencia social reproduce la colonialidad y potenciar la ecología de reconocimientos como práctica descolonial que implica el reconocimiento horizontal de las perspectivas y experiencias de las personas LGTB para producir brechas en la heteronormatividad y abrir caminos de transformación social.

Mientras no haya un desmantelamiento de las jerarquías sociosexuales y de las formaciones ideológicas que soportan la colonialidad, la hegemonía del sistema patriarcal heteronormativo seguirá vigente. Es más, a menudo las prácticas alternativas procedentes del feminismo o de otras teorías críticas no han supuesto una gran amenaza para la hegemonía de este sistema. Audre Lorde (2003) nos recuerda que la transformación de las herramientas del amo es un proceso complejo y duradero que comprende acciones en muchos planos. Sostiene que no es posible desmantelar la casa del amo con sus propias herramientas, en este caso los instrumentos teóricos, metodológicos y sociopolíticos del patriarcado racista, clasista y heterosexista. De ahí la necesidad de otras epistemologías, de otras maneras de reconocer la dignidad plural del ser humano y construir la sociedad que entiendan, con Lorde (2003: 24), que "no son diferencias las que nos inmovilizan sino el silencio. $Y$ hay multitud de silencios que deben romperse". 


\section{Referencias bibliográficas}

Aguiló, A. (2010), "La democracia revolucionaria, un proyecto para el siglo XXI. Entrevista a Boaventura de Sousa Santos", Revista Internacional de Filosofía Política, n $35,117-148$.

Alimonda, H. (coord.) (2011), La naturaleza colonizada. Ecología política y minería en América Latina. Buenos Aires: CLACSO.

AA.VV. (2013), Los deseos olvidados. La perspectiva de género y de diversidad sexual en la Cooperación al Desarrollo, en la Educación para la Ciudadanía Global y en la promoción y defensa de los derechos humanos de las personas inmigrantes y refugiadas. Bilbao: Nahia.

Barbosa, L. y Bensusan, H. (2012). "Por uma international queer: travestis, hijras, muxes e a negociaçao local das alternativas ao cis-heterossexualismo". Anais de Congreso Internacional de Estudos sobre a Diversidade Sexual e de Gênero da ABEH. vol. 1 (1), Salvador, Brasil: UFBA, descargado de: http://abeh.org.br/arquivos_anais/H/H004.pdf [acceso: 15/02/2016].

Barriendos, J. (2011), "La colonialidad del ver. Hacia un nuevo diálogo visual interepistémico", Nómadas, no 35, 13-29, descargado de: http://www.scielo.org.co/pdf/noma/n35/n35a02.pdf [acceso: 14/02/2016]

Berlant, L. y Warnet. M. (2002), “Sexo en público”, en Mérida Jiménez, R. (ed.), Sexualidades transgresoras: una antología de estudios queer. Barcelona: Icaria, 229-257.

Bidaseca, K. y Vázquez Laba, V. (comps.) (2011), Feminismos y poscolonialidad: descolonizando el feminismo desde y en América Latina. Buenos Aires: Godot.

Bourdieu, P. (1985), ¿Qué significa hablar? Economía de los intercambios lingüísticos. Madrid: Akal.

Brah, A. (2004), "Diferencia, diversidad y diferenciación”, en AA.VV., Otras inapropiables. Feminismos desde las fronteras. Madrid: Traficantes de Sueños, 107-136.

Brah, A. y Phoenix, A. (2004), "Ain't I a Woman? Revisiting Intersectionality", Journal of International Women's Studies 5 (3), 75-86.

Butler, J. (2004), Lenguaje, poder e identidad. Madrid: Síntesis.

Carroll, A. y Itaborahy, L. P. (2015), "Homofobia de Estado. Un estudio mundial jurídico sobre la criminalización, protección y reconocimiento del amor entre personas del mismo sexo". Ginebra: ILGA, descargado de: http://old.ilga.org/documents/ILGA_SSHR2015_espanol.pdf [acceso: 16/02/2016].

Carter, D. (2010), Stonewall: The Riots That Sparked the Gay Revolution. New York: Macmillan.

Castro-Gómez, S. (2011), Crítica de la razón latinoamericana. Bogotá: Pontificia Universidad Javeriana.

COGAM (Colectivo de Lesbianas, Gays, Transexuales y Bisexuales de Madrid), Homofobia y bifobia en las aulas 2013. Madrid: COGAM, descargado de: http://www.cogam.es/rs/7595/d112d6ad-54ec-438b-9358- 
4483f9e98868/58b/fd/1/filename/informe-completo-homofobia-en-las-aulas2013.pdf [acceso: 17/02/2016].

Connell, R. (2014), "Margin becoming centre: for a world-centred rethinking of masculinities", NORMA: International Journal for Masculinity Studies, 9 (4), 217231.

Córdoba, D., Sáez, J. y Vidarte, P. (eds.) (2005), Teoría queer: políticas bolleras, maricas, trans, mestizas. Barcelona/Madrid: Egales.

Da Silva, T. (1999), Documentos de identidade: uma introdução às teorias do currículo. Belo Horizonte: Autêntica.

Duberman, M. (2013), Stonewall. New York: Open Road Media.

Fanon, F. (2009), Piel negra, máscaras blancas. Akal, Madrid.

Ferreira, E. (2015), “Desordens no planeta: direitos LGTB”, en Ferreira, E. et al (orgs.), Percursos feministas: desafias os tempos. Lisboa: UMA/Universidade Feminista.

Foucault, M. (1997), Arqueología del saber. México, D, F.: Siglo XXI.

Focault, M. (2007), Historia de la sexualidad, volumen 1: La voluntad de saber. México, D. F.: Siglo XXI.

Galofre, P. y Missé, M. (eds.) (2015), Políticas trans. Una antología de textos desde los estudios trans norteamericanos. Barcelona/Madrid: Egales.

Guasch, Ó. (2000), La crisis de la heterosexualidad. Barcelona: Laertes.

Herrera Flores, J. (2008), La reinvención de los derechos humanos. Sevilla: Atrapasueños.

Herrera Gómez, C. (2010), Más allá de las etiquetas. Mujeres, hombres y trans. Tafalla: Txalaparta.

Hill Collins, P. (2000), Black Feminist Thought: Knowledge, Consciousness, and the Politics of Empowerment. New York: Routledge.

Hulko, W. (2009), "The Time -and Context- Contingent Nature of Intersectionality and Interlocking Oppressions", Affilia: Journal of Women and Social Work, vol. 24, 44-55.

Illouz, E. (2009), El consumo de la utopía romántica. El amor y las contradicciones culturales del capitalismo. Buenos Aires: Katz.

Jagose, A. (1996), Queer Theory: An Introduction. New York: New York University Press.

Kelliher, D. (2014), "Solidarity and Sexuality: Lesbians and Gays Support the Miners 1984-5", History Workshop Journal, 77 (1), 240-262.

Kirsch, M. (2013), Queer Theory and Social Change. New York: Routledge.

Kosofsky Sedgwick, E. (1998), Epistemología del armario. La Tempestad: Barcelona.

Paredes, J. (2008), Hilando fino desde el feminismo comunitario. La Paz: CEDEC/Mujeres Creando Comunidad. 
Piscitelli, A. (2008), "Interseccionalidade, categorias de articulação e experiências de migrantes brasileiras", Sociedade e Cultura, vol.11, n 2, 263274, descargado de: http://www.redalyc.org/pdf/703/70311249015.pdf [acceso: 15/02/2016].

Quijano, A. (2000), "Colonialidad del poder, eurocentrismo y América Latina", en Lander, E. (comp.), La colonialidad del saber: eurocentrismo y ciencias sociales. Perspectivas latinoamericanas. Buenos Aires: CLACSO, 201-246.

Quijano, A. (2007), "Colonialidad del poder y clasificación social", en CastroGómez, S. y Grosfoguel, R. (eds.), El giro decolonial: reflexiones para una diversidad epistémica más allá del capitalismo global. Bogotá: Pontificia Universidad Javeriana/Siglo del Hombre Editores/IESCO-UC.

Lagarde, M. (2000), Claves feministas para la autoestima de las mujeres. Madrid: Horas y Horas.

Lander, E. (comp.) (2000), La colonialidad del saber: eurocentrismo y ciencias sociales. Perspectivas latinoamericanas. Buenos Aires: CLACSO.

León, I. y Mtetwa, P. (eds.) (2003), Globalización: alternativas GLBT. Quito: Diálogo Sur/Sur GLBT.

Loovas, K. et al. (eds.) (2013), LGBT Studies and Queer Theory: New Conflicts, Collaborations, and Contested Terrain. Binghamton: Harrington Park Press.

Lorde, A. (2003), La hermana, la extranjera: artículos y conferencias. Madrid: Horas y Horas.

Lugones, M. (2008), “Colonialidad y género", Tabula Rasa, n 9, 73-101, descargado de: http://www.revistatabularasa.org/numero-9/05lugones.pdf [acceso: 09/02/2016].

Maldonado-Torres, N. (2007), "On the Coloniality of Being: Contributions to the Development of a Concept". Cultural Studies, n 21 (2-3), 240-70.

McClintock, A. (1995), Imperial Leather: Race, Gender, and Sexuality in the Colonial Contest. New York: Routledge.

Missé, G. y Coll-Planas, G. (eds.) (2010), El género desordenado. Críticas en torno a la patologización de la transexualidad. Barcelona/Madrid: Egales.

Mignolo, W. et al. (comp.) (2008), Género y descolonialidad. Buenos Aires: Ediciones del Signo.

Mignolo, W. (2003), Historias locales/diseños globales: colonialidad, conocimientos subalternos y pensamiento fronterizo. Madrid: Akal.

Montes, A. y Busso, H. (2007), "Entrevista a Ramón Grosfoguel”, Polis, $\mathrm{n}^{\circ} 18$, descargado de: http://polis.revues.org/4040 [acceso: 08/02/2016].

Pereira, P. P. (2015), "Queer decolonial: quando as teorias viajam", Contemporânea - Revista de Sociologia da UFSCar, v. 5, n 2, 411-437, descargado de: http://www.contemporanea.ufscar.br/index.php/contemporanea/article/view/340/ 146 [acceso: 15/02/2016].

Plummer, K. (2003), Intimate Citizenship: Private Decisions and Public Dialogues. Seattle: University of Washington Press. 
Rubin, G. (1986), "El tráfico de mujeres: notas sobre la 'economía política del sexo"', Revista Nueva Antropología, vol. VIII, n³ 30, 95-145.

Sabariego, J. (2004), "Un deseo de ser piel roja: iteraciones, referencialidades y reflexividades contextuales e históricas de la Queer Theory", Crítica Jurídica, ${ }^{\circ}$ 23, 130-147, descargado de: http://www.juridicas.unam.mx/publica/librev/rev/critica/cont/23/mng/mng7.pdf [acceso: 13/02/2016].

Santos, A. C. (2013), Social Movements and Sexual Citizenship in Southern Europe. Basingstoke: Palgrave Macmillan.

Santos, B. S. (1998), De la mano de Alicia: lo social y lo político en la postmodernidad. Bogotá: Siglo del Hombre Editores/Facultad de Derecho Universidad de los Andes.

Santos, B. S. (2005), El milenio huérfano. Ensayos para una nueva cultura política. Madrid: Trotta/ILSA.

Santos, B. S. (2006), Renovar la teoría crítica y reinventar la emancipación social (encuentros en Buenos Aires). Buenos Aires: CLACSO.

Santos, B. S. (2009), Una epistemología del Sur: la reinvención del conocimiento y la emancipación social. México: Siglo XXI/CLACSO.

Santos, B. S. (2010), Refundación del Estado en América Latina. Perspectivas desde una Epistemología del Sur. Lima: IIDS-IILS y Programa Democracia y Transformación Global.

Santos, B. S. (2011), "Epistemologías del Sur”. Utopía y praxis latinoamericana, vol. 16, $\mathrm{n}^{\circ}$ 54, 17-39, descargado de: http://www.redalyc.org/articulo.oa?id=27920007003 [acceso: 10/02/2016].

Santos, B. S. (2012), "Public Sphere and Epistemologies of the South", Africa Development, XXXVII (1), 43-67.

Santos, B. S. y Meneses. M. P. (eds.) (2014), Epistemologías del Sur (perspectivas). Madrid: Akal.

Thiong'o, N. (1994), Decolonising the mind: the politics of language in African literature. Nairobi: East African Publishers.

Tosh, J. (2015), Perverse Psychology: The Pathologization of Sexual Violence and Transgenderism. New York: Routledge.

Trujillo, G. (2014), "De la necesidad y urgencia de seguir queerizando y transformando el feminismo. Unas notas para el debate desde el contexto español", Ex æquo, $\mathrm{n}^{\circ}$ 29, 55-67, descargado de: http://www.scielo.mec.pt/pdf/aeq/n29/n29a05.pdf [acceso: 15/02/2016].

Wallerstein, I. (1999), Impensar las ciencias sociales: límites de los paradigmas decimonónicos. México, D. F.: Siglo XXI.

Walsh, C. (2008), "Interculturalidad, plurinacionalidad y decolonialidad: las insurgencias político-epistémicas de refundar el Estado", Tabula Rasa, n 9, 131-152, descargado de: http://www.revistatabularasa.org/numero9/08walsh.pdf [acceso: 09/02/2016]. 